\title{
COMPARISON OF METHODS FOR DISPERSION MODELLING OF CONTAMINANTS FROM INDUSTRIAL SOURCES
}

\author{
GRZEGORZ KRAJEWSKI \& KRZYSZTOF LIS \\ KGHM Cuprum Ltd. Research and Development Centre, Poland
}

\begin{abstract}
The method for determining the dispersion of pollutants for industrial sources in force in Poland is based on a simple Gaussian plume model based on the wind rose and Pasqual's atmosphere stability classes. Air pollution has become a growing concern in the past few years in Poland and implementing new more advanced model is being considered. In order to illustrate the limitations of current method was compared with an advanced multilayer puff CALPUFF Gaussian model. Modelling of the spread of pollutants in ambient air was conducted based on the same source parameters. Industrial source with very high flow and low height was selected as good example to compare both methods. Spatial variability of the annual averages of air pollutant concentrations was obtained in computing grid with high density. Meteorological conditions for CALPUFF were determined using a diagnostic meteorological model CALMET based on meteorological data from surface stations and radar surveys. The results of calculations indicated that pollutant emissions from both methods differs in concentration and the distance of the highest concentrations relative to the source. For the advanced model, a greater dispersion of pollutants in the ambient air was obtained as well as higher maximum values registered for receptors in the vicinity of the source.

Keywords: air quality, pollutant dispersion models, Gaussian plume model, Gaussian puff model.
\end{abstract}

\section{INTRODUCTION}

Air pollution has become a growing concern in the past few years in Poland for several reasons. One of them is the increasingly stringent air quality standards, enforcing a number of restrictions for both industry and private individuals. Another important factor is the growing social awareness regarding the state of air quality and its impact on health. The method for determining the dispersion of pollutants for industrial sources in force in Poland is based on a simple Gaussian plume model . Model is based on the wind rose and Pasqual's atmosphere stability classes and is over fifty years old [1]. In Poland it is being considered implementing of a new advanced model which takes into account a broader range of meteorological geophysical data, such as CALPUFF [2].

\section{METHODOLOGY}

\subsection{Model assumptions}

Conducted modelling of the spread of pollutants in ambient air was based on the same source parameters. The exhaust air from industrial source with high flow and low height was selected as the good example to compare both methods. The location of the emitter and its parameters are hypothetical. The source under consideration was modelled as a point source with the following parameters:

- Stack height above ground level: $10 \mathrm{~m}$

- Stack diameter: $5.6 \mathrm{~m}$

- Gas flow rate: $1,000,000 \mathrm{~m}^{3} / \mathrm{h}$ 
- Exit velocity: $11.1 \mathrm{~m} / \mathrm{s}$

The emission of two pollutants was considered: $\mathrm{PM}_{10}$ and $\mathrm{NO}_{\mathrm{x}}$ (the sum of $\mathrm{NO}$ and $\mathrm{NO}_{2}$ expressed as $\mathrm{NO}_{2}$ ). The following emission values were assumed during the year:

- $\quad \mathrm{PM}_{10}: 1.0 \mathrm{~kg} / \mathrm{h}$

- $\mathrm{NO}_{\mathrm{x}}: 5.0 \mathrm{~kg} / \mathrm{h}$

Continuous work of emission source throughout the year was assumed. The location of the emitter was adopted in a diversified area encompassing rural areas, forest and other green areas (pastures). A rather dense computing grid with a step of $100 \mathrm{~m}$ covering an area of $5 \mathrm{x}$ $5 \mathrm{~km}$ was assumed, the source was located in the middle of the grid. Modelling was conducted on the ground level.

Due to the wider range of variables used by the CALPUFF model, data range most consistent with the Pasquill model was selected. In order to compare both models, the focus was mainly on the impact of meteorological and spatial data on pollutant concentrations. Wet and dry deposition were not considered. Both models do not include background pollution.

\subsection{CALPUFF model}

CALPUFF as advanced multilayer Gaussian puff model requires a number of meteorological and geophysical data [3]. Lack of regulation allows for relative latitude in relation to sources of data acquisition. Nevertheless, the data was collected from the most reliable sources possible. Spatial data of land area were obtained from digital terrain model Shuttle Radar Topography Mission (SRTM3) and land cover database CORINE Land Cover 2006 (CLC 2006) with resolution of about $100 \mathrm{~m}$ (Fig. 1(a)). Land cover data were reclassified from 44 to 6 classes (Fig. 1(b)), and processed by the CTGPROC pre-processor [4], [5].

Meteorological conditions were determined using a diagnostic meteorological model CALMET based on meteorological data from radar surveys and three surface stations. Hourly meteorological grid with a resolution of $100 \mathrm{~m}$ was prepared for 2017. Spatial variability of

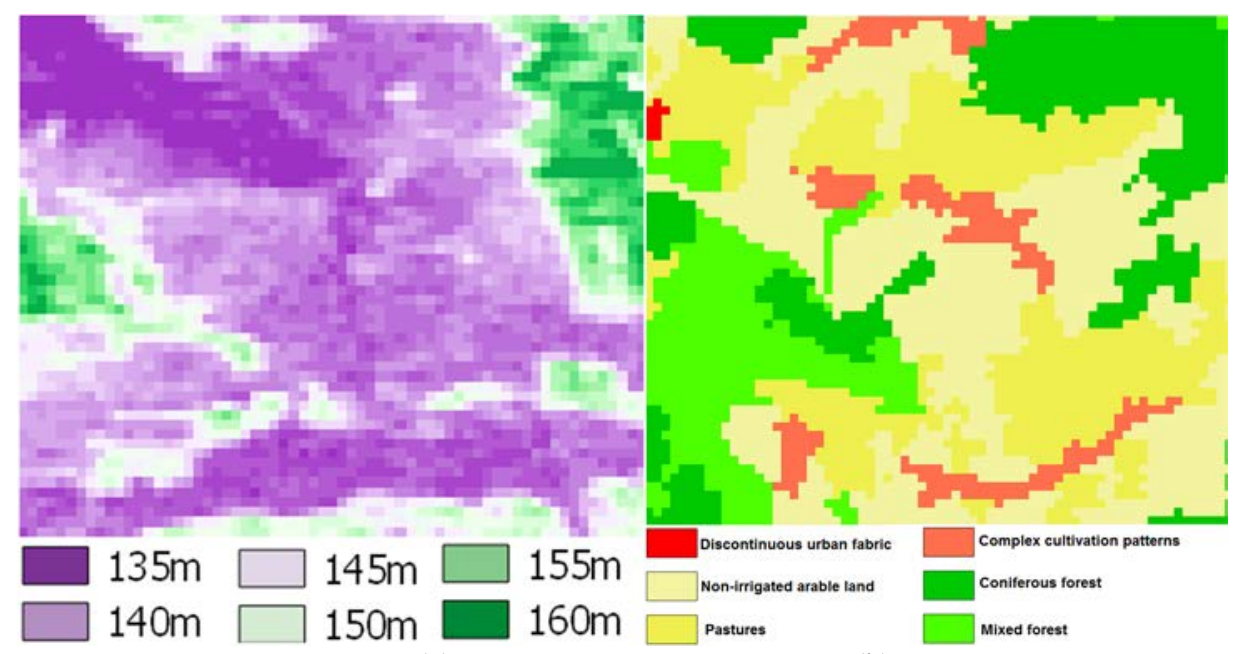

(a)

(b)

Figure 1: Spatial data. (a) Terrain; (b) Land cover. 
the annual averages of air pollutant concentrations was obtained in computational grid with density of $100 \mathrm{~m}$, covering area of $5 \times 5 \mathrm{~km}$. Sampling grid identical to the computational grid was used with a nesting factor of one.

\subsection{Pasquill model}

Currently used in Poland methodology is based on the model proposed by Pasquill, a classic first generation Gaussian plume model. It is based on the formula of the diffusion equation developed by Pasquill. In comparison to the models of the second generation, this model does not take into account the temporal and three-dimensional variability of the meteorological field. The calculation area in the model is treated as flat. Chemical changes, deposition of pollutants and the variability of the terrain are also not included.

Meteorological data is entered into the model in the form of a wind rose created on the basis of wind speed and direction observations in a given geographical area. The rose is based on average of several years of observation. The model used data from nearest meteorological station divided into two periods: the heating season (winter) and summer season.

The type of land cover in the area of calculation was introduced into the model in the form of roughness coefficient expressed in meters. According to the mythological assumptions [2], one value should be introduced for the entire computational grid. Value is calculated as the average roughness for individual areas within the calculation range, according to their size. For the area in question, this value amounted to $0.628 \mathrm{~m}$.

\section{RESULTS}

The table below presents a summary of modelling results for both compared models. The average annual values recorded for all receptors were compared. Average concentration value for the whole area and the maximum and minimum value for particular receptors have been specified.

Significant differences in the detail and type of data entered into the models cause the results to be noticeably different from each other. This is particularly evident in case of maximum values registered for receptors in the vicinity of the source. The CALPUFF model in comparison with the reference methodology calculated values twice higher for $\mathrm{NO}_{\mathrm{x}}$ and more than three times higher for $\mathrm{PM}_{10}$. Such significant discrepancies are probably due to the inability to use Pasquill model at wind speeds below $1 \mathrm{~m} / \mathrm{s}$.

The average concentration of $\mathrm{PM}_{10}$ dust for the whole area is higher for the CALPUFF model, however in the case of $\mathrm{NO}_{\mathrm{x}}$ it is smaller than for the reference methodology.

To illustrate the spatial distribution of pollutants, the average concentrations at ground level are presented below.

For $\mathrm{PM}_{10}$ dust, a much larger spatial distribution in the Gaussian puff model is visible. The greatest discrepancy can be observed with lower concentrations of dust below $5 \mu \mathrm{g} / \mathrm{m}^{3}$, for which the occupied area is several times larger than for the Pasquill model. For the puff model, the direction of migration of pollutants is directed towards the north and south.

Table 1: Average annual values recorded for all receptors.

\begin{tabular}{|l|c|c|c|c|c|c|}
\hline \multirow{3}{*}{ Substance } & \multicolumn{4}{|c|}{ Average annual values recorded for all receptors $\left(\mu \mathrm{g} / \mathrm{m}^{3}\right)$} \\
\cline { 2 - 7 } & \multicolumn{3}{|c|}{ CALPUFF model } & \multicolumn{3}{c|}{ Pasquill model } \\
\cline { 2 - 7 } & min. & max. & avg. & min. & max. & avg. \\
\hline $\mathrm{PM}_{10}$ & 0,001 & 0,893 & 0,024 & 0,000 & 0,245 & 0,014 \\
\hline $\mathrm{NO}_{\mathrm{x}}$ & 0,006 & 4,441 & 0,116 & 0,000 & 2,449 & 0,139 \\
\hline
\end{tabular}




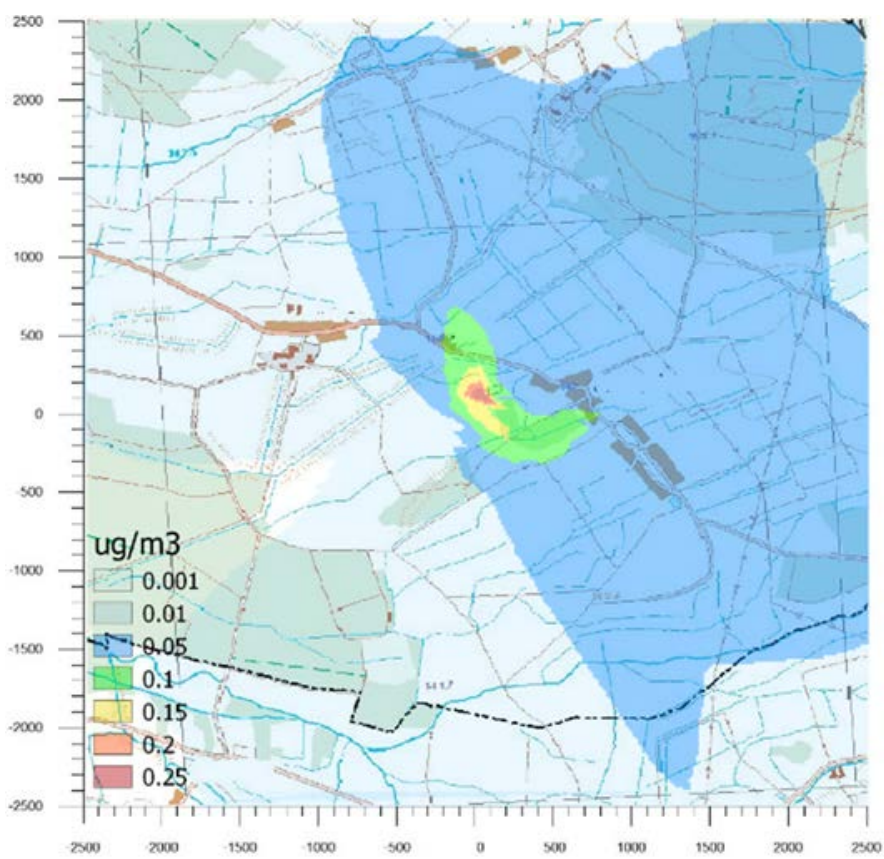

Figure 2: $\mathrm{PM}_{10}$ average concentration at ground level - CALPUFF model.

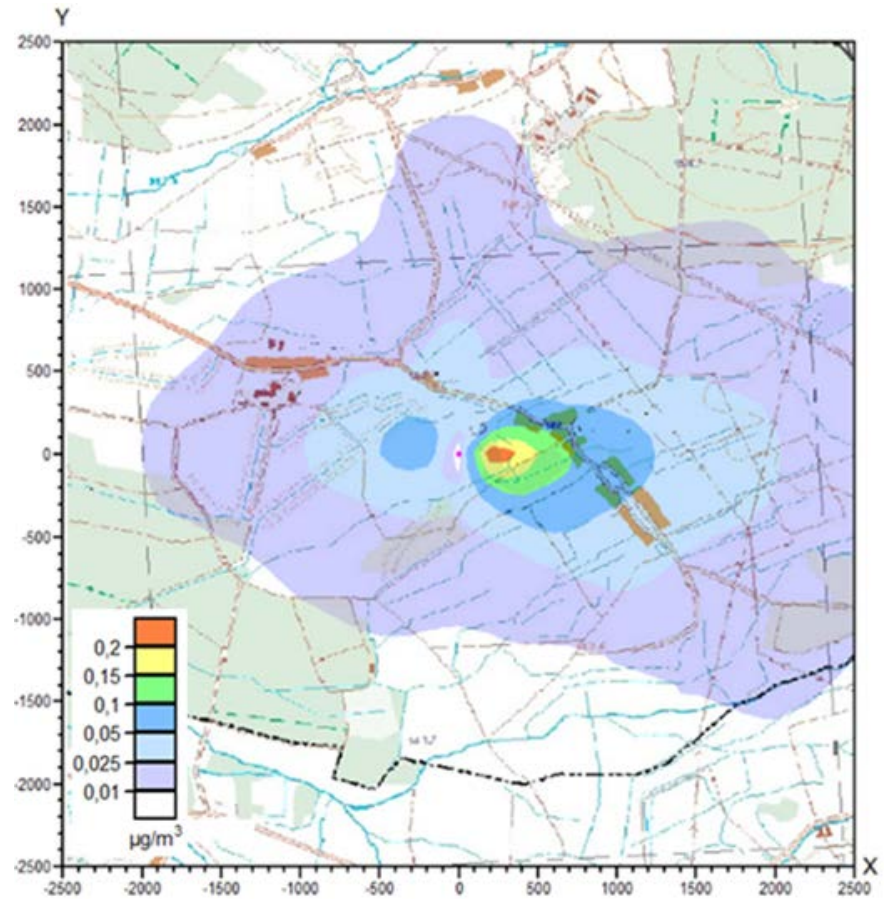

Figure 3: $\mathrm{PM}_{10}$ average concentration at ground level - Pasquill model. 


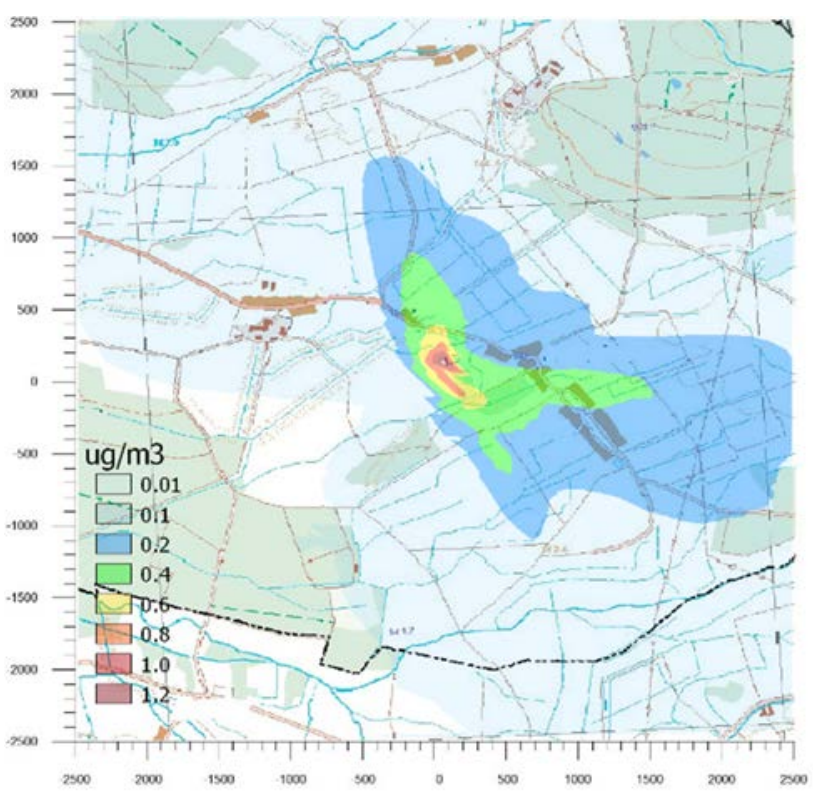

Figure 4: $\mathrm{NO}_{\mathrm{x}}$ average concentration at ground level - CALPUFF model.

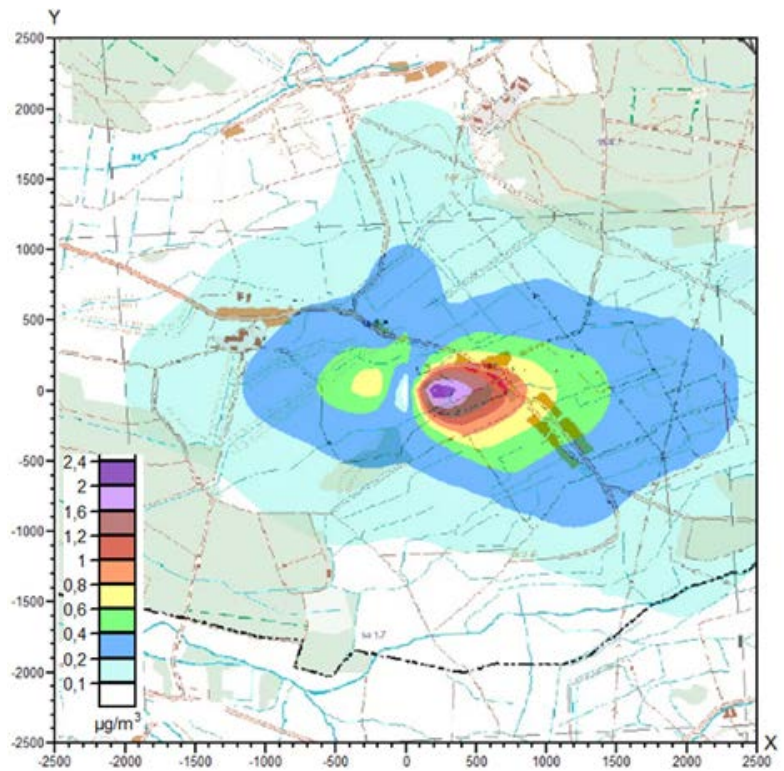

Figure 5: $\mathrm{NO}_{\mathrm{x}}$ average concentration at ground level - Pasquill model.

In the case of $\mathrm{NO}_{\mathrm{x}}$ concentration, a much larger spatial distribution in the CALPUFF is visible. In contrast to dust, for $\mathrm{NO}_{\mathrm{x}}$ the greatest differences can be observed at high concentration values. The direction of pollutant migration is also different. Similarly, to 
$\mathrm{PM}_{10}$, it is directed towards the north and south. Differences in the direction of migration of pollutants probably arise from different periods of wind speed and direction measurements.

\section{CONCLUSIONS}

The purpose of this work was to compare the Gaussian plume model with the more modern Gaussian puff model. The current methodology was compared with the CALPUFF model. In order to compare both models, the focus was mainly on the impact of meteorological and spatial data on pollutant concentrations. Background pollution, wet and dry deposition were not considered.

Calculations made using the CALPUFF model have shown a higher maximum values for receptors in the vicinity of the source. Differences in the direction of migration and greater dispersion of pollutants were also observed. Discrepancies in values obtained for both models are probably due to the inability to use Pasquill model at wind speeds below $1 \mathrm{~m} / \mathrm{s}$ and differences in meteorological data.

Based on the calculations made, it can be assumed that the impact of meteorological data on the obtained values is crucial, especially if it translates into legal regulations. Therefore, when entering a new method, the source and scope of meteorological data should be strictly defined.

\section{ACKNOWLEDGEMENT}

This work was supported by Polish Ministry of Science and Higher Education.

\section{REFERENCES}

[1] Pasquill, F., Atmospheric Diffusion, 2nd ed. Ellis Horwood Limited, Chichester, 1974. ISBN: 0853120153.

[2] Fijołek, M. \& Juda-Rezler, K., New challenges in air quality and climate modelling. Archives of Environmental Protection, 36(1), pp. 3-28, 2010.

[3] Scire, J. et al., A user's guide for the CALMET meteorogical model (version 5). Earth Tech, Inc., 2010.

[4] Oleniacz, R. \& Rzeszutek, M., Determination of optimal spatial databases for the area of Poland to the calculation of air pollutant dispersion using the CALMET/CALPUFF model. Geomatics and Environmental Engineering, 8, pp. 57-69, 2014.

[5] British Columbia Ministry of Environment, British Columbia Air Quality Dispersion Modelling Guideline, Victoria, 2015. 